\title{
Numerical Studies of Deformations and Crack Propagation in Reinforced Concrete Annular Sections Under Thermopower Loads
}

\author{
I.I. Karkhut Ph.D*, \\ Assistant professor $N U$ «LP» \\ J.J. Luchko Dr.Sc**, \\ Professor LNAU \\ V.V. Kirichok M.Sc ${ }^{* * * *}$ \\ Leading Engineer, Lira group of companies
}

\begin{abstract}
The article describes the current state and the level of research of annular cross-sections of structures of energy facilities operating under conditions of thermal and force effects. The results of a numerical experiment to study the deformability and crack resistance of annular cross-sections and their comparison with the results of testing physical models of fragments of reinforced concrete chimneys are presented. It is shown that at the modern level of development of the mathematical apparatus and computer calculation programs, using the deformation model, the deviation does not exceed $20 \%$. The described research results of other authors and this work confirm the possibility of replacing cost and long-term field tests with numerical experiments.
\end{abstract}

Key words: reinforced concrete ring, thermal power loads, numerical experiment

Introduction. Modern research of reinforced concrete annular cross-sections of structures Trends in the development of engineering practice show that the problem of monitoring the thermally stressed state of elements of engineering structures with the simultaneous provision of reliable conditions for their operation is becoming urgent. Reliable operation of constructed energy facilities, including those with sources of ionizing radiation, requires reliable modern calculation methods to obtain reliable data on the effect on materials and structures. Replacing cost and lengthy field tests with reliable numerical calculation methods is an urgent need to accelerate the development of this industry.

\footnotetext{
*email address: karkhoot1@ gmail.com, ORCID 0000-0002-9205-5118 ** email address: lychco.diit@ gmail.com, ORCID 0000-0002-3675-0503 *** email address: k0965976337@gmail.com, ORCID 0000-0002-4359-7148
} 


\section{Analysis of scientific and technical sources.}

At energy facilities, a lot of research has been carried out on annular reinforced concrete sections, which are under the influence of temperature and power loads [1-8], including those with external sheet reinforcement.

The authors of work [1] carried out research and developed the design of a sealing shell with double external reinforcement. This design provided the required level of fracture toughness of the structure.

Thus, in [2], the quantitative contribution of the effect of temperature drops on the stress in the reinforced concrete annular section and the outer steel shell of the hydraulic tunnel was analyzed. The stresses in the layers of the annular section were determined. It was concluded that the functioning of such a structure with temperature drops in the coolant can be simulated in a numerical experiment with high accuracy. The approach to mathematical modeling and the results of numerical analysis of physical experiments on annular specimens with double external reinforcement were carried out in [1, 3-5]. It was shown that a numerical experiment made it possible to take into account the temperature deformations of concrete with sufficient accuracy and to reduce the costs of research and design.

In [6], the results of the study of the annular beam of the NPP containment are presented. The importance of taking into account the processes of concrete heating in time for an accurate analysis of stresses in an annular section is indicated.

Such an analysis was also carried out in [7] for annular reinforced concrete cross sections under the influence of temperature loads, in which the main influence at an early age on the stressstrain state under temperature loads is created by shrinkage and hydration of concrete. It is shown that the models applied for the numerical analysis give insignificant deviations from the full-scale experiment.

Theoretical dependencies for calculating stresses in thin annular cross-sections of concrete chimneys and their computer analysis based on linear approximation are given in [8]. The influence of heating of the outer face on the stress in concrete with an annular section is considered. The importance of taking into account temperature effects for the design of reinforcement and the possibility of using numerical analysis is shown.

It is more expedient for numerical analysis to apply a nonlinear approximation taking into account the positions of the deformable model [9] and numerically simulate temperatures 
significantly higher than $50^{\circ} \mathrm{C}$, at which the effect of temperature on concrete should be taken into account.

The authors of [10] carried out numerous studies of the deformability and crack resistance of annular elements of protective reinforced concrete structures under the action of internal pressure and one-sided heating up to $150^{\circ} \mathrm{C}$. The results of experimental studies carried out on rings with bar reinforcement of periodic profile were analyzed by V.A. Kostornichenko and A.P. Krichevsky [10]. It was found that the processes of cracking in annular specimens are caused by the presence of temperature bending moments, which depend on the temperature difference in the section, the type and nature of the reinforcement. Since all the studied annular specimens had the same cross-section and percentage of reinforcement (Fig. 1a), the main influence on the cracking processes was created by the nature of the temperature distribution along the height of the cross-section, the duration of the temperature load and the strength characteristics of concrete.

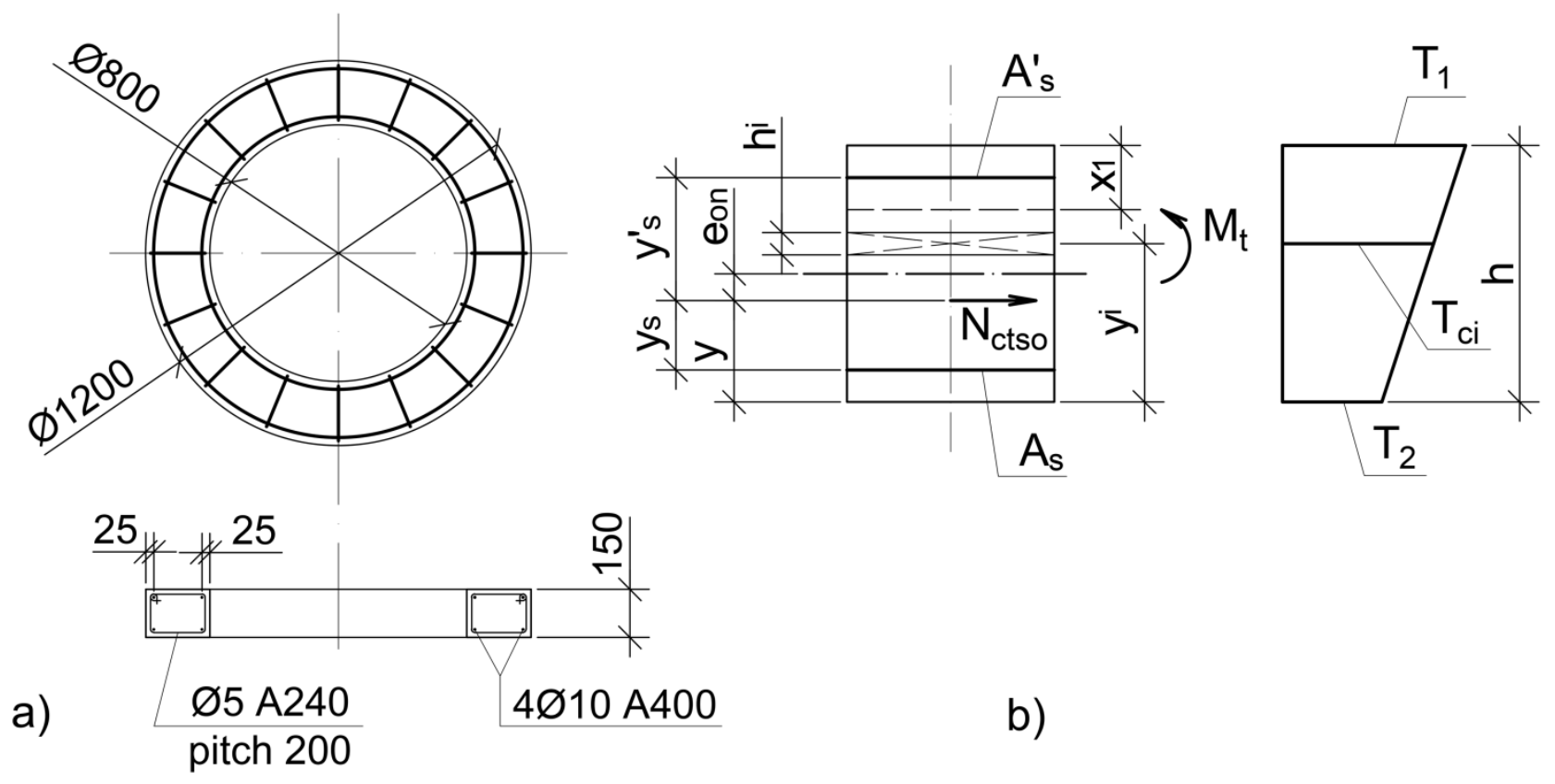

1. The design of the annular sample a) and the design scheme b).

The characteristics of the ring fragments that were investigated by

V. A. Kostornichenko [10] were taken for numerical studies, given in table 1. 
Table 1.

\begin{tabular}{|c|c|c|c|c|c|}
\hline \multirow{2}{*}{$\begin{array}{l}\text { Sample } \\
\text { code }\end{array}$} & \multirow{2}{*}{$\begin{array}{l}\text { Reinforcement } \\
\text { strength } f_{y}, \mathrm{MPa}\end{array}$} & \multicolumn{2}{|c|}{ Concrete strength, $\mathrm{MPa}$} & \multicolumn{2}{|c|}{ load } \\
\hline & & $f_{\text {c. prism }}$ & $f_{c t m}$ & $\mathrm{~T},{ }^{\circ} \mathrm{C}$ & $\mathrm{P}_{0}$ \\
\hline K8-1 & 477,3 & 34,6 & 1,84 & $150 / 60$ & - \\
\hline K8-2 & 477,3 & 34,6 & 2,00 & $150 / 60$ & + \\
\hline K7-1 & 476,0 & 30,0 & 2,20 & $20 / 60$ & cyclic \\
\hline K7-2 & 476,0 & 31,0 & 2,20 & $20 / 60$ & cyclic \\
\hline K5-1 & 477,5 & 34,8 & 2,00 & $150 / 60$ & - \\
\hline К5-2 & 477,5 & 34,8 & 2,02 & $150 / 60$ & + \\
\hline
\end{tabular}

A feature of the experimental studies [10] was that the internal pressure was created by heated cement, and the thermocouples measured the air temperature at the edges of the annular elements. Table 1 shows the concrete temperature of the outer edge of the ring. The ambient temperature was $20^{\circ} \mathrm{C}$ and convective heat exchange took place.

It was found that the first cracks in the rings were formed at a temperature difference along the height of the cross-section of $\approx 46^{\circ} \mathrm{C}$. The temperature moments of cracking were 2.24-2.48 $\mathrm{kNm}$. The maximum temperature moments, which during short-term tests were $3.0 \mathrm{kNm}$, decreased to $0.85 \mathrm{kNm}$ under prolonged exposure to temperature, and changed sign when cooled to normal temperature and amounted to $-2.4 \mathrm{kNm}$. The moments of cracking depend on the heterogeneity of the concrete along the height of the cross-section, plastic deformations of the concrete and the non-linear temperature distribution in the cross-section. The annular force at which cracks began to form at normal temperature was $35.8 \mathrm{kN}$. With a temperature difference of $110^{\circ} \mathrm{C}$, it decreased to $5.97 \mathrm{kN}$. A decrease in the magnitude of the cracking force by $4.2-5.3 \%$ was revealed with a curvilinear temperature diagram (non-stationary mode). In force tests and normal temperature, through cracking was recorded at a tensile annular force of $30 \mathrm{kN}$.

The crack opening width $w_{\text {crc }}$ in reinforced concrete rings with short-term heating was $0.1 \mathrm{~mm}$, with long-term heating $-0.075 \mathrm{~mm}$. In force tests, the crack opening width did not exceed 0.2 $\mathrm{mm}$ at the level of $80 \%$ of the breaking tensile force in the section. Cooling to normal temperature led to a decrease in the crack opening width to $0.025 \mathrm{~mm}$. 
An increase in the temperature gradient along the height of the cross-section from 40 to $110^{\circ}$ C together with short-term tensile forces from internal pressure at the level of 0.8 from the breaking pressure led to an increase in the width of the opening of normal cracks from 0.25$0.275 \mathrm{~mm}$ to $0.3-0.312 \mathrm{~mm}$, respectively.

The maximum height of non-through normal cracks was $5.9 \mathrm{~cm}$ for the first short-term heating, $6.33 \mathrm{~cm}$ for the long-term first heating, $6.4 \mathrm{~cm}$ for the re-heating. Cooling of the rings after heating led to the formation of through cracks in the cross sections, for which the maximum opening width was fixed with one-sided heating of the inner face. In other cross-sections, the height of non-through cracks was fixed at $3.9 \mathrm{~cm}$.

With prolonged exposure to elevated temperatures and temperature differences along the height of the cross-section, the crack opening width remained practically unchanged. The height and width of the crack opening did not increase with repeated heating of the inner face of the ring. The author [9] concluded that the reason for this was a decrease in temperature moments and the development of concrete shrinkage processes, which compensated each other. The relative deformations of the longitudinal axis of the rings with short-term heating of the inner face of the rings were $(53,7-57,2) \cdot 10^{-5}$, with prolonged heating $19,2 \cdot 10^{-5}$. Since the stress in the concrete in the compression zone of the rings was insignificant, the distribution of deformations along the height was assumed to be linear, and the stress was assumed to be elastic.

In experimental studies, the stress of the most heated compressed face of the concrete of the rings was 2.5-3.0 $\mathrm{MPa}$. The stresses in the longitudinal working reinforcement of the rings, measured in the course of experimental studies, amounted to 38-43 MPa under short-term and long-term exposure to internal pressure. Additional temperature stresses in this case were 20.8524.16 MPa with short-term heating and increased to 100.65-109.26 with prolonged exposure to elevated temperature.

The current standards [10] recommend taking into account additional stresses in the reinforcement from the temperature shrinkage of concrete at the level of $60 \mathrm{MPa}$ and not taking into account the work of tensile concrete in the limiting state. The modulus of deformation of concrete at elevated temperatures of $60-120^{\circ} \mathrm{C}$ decreased by $24-40 \%$, respectively.

According to the results of the analysis of experiments, it is concluded that the establishment of the moment diagram is influenced by the appearance of an additional force $\mathrm{N}_{\mathrm{ctso}}$ (fig. 1b) 
with an eccentricity $e_{o n}$, depending on the development of plastic deformations of concrete and the temperature difference along the height of the ring cross section.

The additional force Nctso, calculated taking into account the already existing balanced diagram of temperature moments in the annular section, was $12.2 \mathrm{kN}$ with short-term heating and $43.0 \mathrm{kN}$ with long-term heating. This force reduced the moment of cracking in the rings by $14 \%$ at a temperature near the inner edge of $60^{\circ} \mathrm{C}$ and by $26 \%$ with an increase in temperature to $150^{\circ} \mathrm{C}$. A decrease in the strength of concrete when heated led to a decrease in the magnitude of the moment of cracking by $3-8 \%$. The nonlinear distribution of temperatures along the height of the cross section during the first short-term heating led to a decrease in the moment of cracking by $5.6 \%$ at a temperature near the inner edge of $60^{\circ} \mathrm{C}$ and by $5.3 \%$ with an increase in temperature to $150{ }^{\circ} \mathrm{C}$. The work of tensioned concrete between cracks in accordance with recommendations of the norms [11] was taken into account using the coefficient $\Psi_{\mathrm{s}}$. It is recommended to take into account the presence of cracks with tensile forces in the ring at the level of $30 \mathrm{kN}$.

\section{Numerical experiment technique}

Numerical studies of ring fragments were carried out in the Lira 10.8 software package by the finite element method in a physically nonlinear formulation. The purpose of the research was to verify the developed algorithms in the formulation of a stationary temperature problem using the provisions of the deformation model, which is adopted in the current standards. The possibility of replacing cost full-scale tests with numerical modeling was tested. As initial data, we used the actual dimensions of the sections, reinforcement of annular specimens and strength reinforcement and concrete (Fig. 1, Table 1). Internal pressure was applied in steps of 0.25 of the maximum, the effect of which caused the appearance of the tensile force in the section, which was achieved in experimental studies. The relationship between the internal pressure $\mathrm{P}_{0}$ and the tensile annular forces was adopted according to the known dependencies of structural mechanics.

The stationary problem of thermal conductivity was modeled taking into account the data of experimental studies - the actual temperature level at the surface of the concrete faces of the rings. In this case, the temperature distribution over the depth of the samples in the numerical experiment corresponded to the physical experiment. 
The concrete ring was modeled using volumetric elements, longitudinal reinforcement and transverse stirrups were modeled using bar elements with appropriate stiffness and location. Temperature loads were applied to the inner and outer parts of the ring. As the physical properties of the base of the ring, characteristics were taken that corresponded to heavy concrete on Portland cement. The boundary conditions ensured free support of the ring on the surface. Two types of temperature boundary conditions for the outer surface of the ring were tested. In the first variant, the boundary condition was a fixed temperature of the outer face of $60^{\circ} \mathrm{C}$. In the second variant, the boundary conditions of Newton-Richman surface heat exchange were applied with the temperature of the outer edge of $60^{\circ} \mathrm{C}$ and the ambient temperature of $20^{\circ} \mathrm{C}$. The second variant made it possible to take into account the fact that in a real experiment the temperature was measured not of the ring itself, but the temperature of the environment that surrounds it.

\section{Comparison and analysis of the results of numerical and physical experiments}

The study of the effect of the tensile strength of concrete on the level of stresses in the reinforcement, the processes of cracking and the deformability of rings was of considerable interest for numerical analysis.

The results of the numerical determination of the crack opening width $w$, the height of the compressed concrete zone $x_{1}$ and the maximum tensile stresses $\sigma_{s 1, \max }$ in the reinforcement are given in Tables 2 and 3. In this case, the crack opening width was calculated according to the method described in [9]. All initial data for this dependence were obtained by the finite element method. Table 2 shows the results of a numerical experiment without taking into account the tensile strength of concrete, which can also simulate the operation of samples with smooth reinforcement, the adhesion of which to concrete significantly deteriorates when heated.

Table 2.

Numerical experiment results $\left(f_{c t m}=0.2 \mathrm{MPa}\right)$

\begin{tabular}{|l|l|l|l|l|l|}
\hline $\begin{array}{c}\mathrm{P}_{0,} \\
\mathrm{MPa}\end{array}$ & \multicolumn{1}{|c|}{$\mathrm{T}_{1},{ }^{\circ} \mathrm{C}$} & \multicolumn{1}{c|}{$\mathrm{T}_{2},{ }^{\circ} \mathrm{C}^{*}$} & $\sigma_{s 1, \max , \mathrm{MPa}}$ & $x_{1}, \mathrm{~mm}$ & $w_{c r c}, \mathrm{~mm}$ \\
\hline 0 & 150 & 60 & 89 & 25 & 0,0433 \\
\hline 0.5 & 150 & 60 & 140 & 0 & 0,111 \\
\hline 1,0 & 150 & 60 & 220 & 0 & 0,215 \\
\hline 1,5 & 150 & 60 & 299 & 0 & 0,317 \\
\hline 2,0 & 150 & 60 & 379 & 0 & 0,421 \\
\hline 2,0 & 20 & 20 & 429 & 0 & 0,486 \\
\hline
\end{tabular}


Note: $*$ - convective heat transfer on the outer part of the ring (Newton-Richmann boundary condition).

$\mathrm{P}_{0}$ - internal pressure, $\mathrm{T}_{1}, \mathrm{~T}_{2}$ - respectively the temperatures inside and outside the ring, $\sigma_{s 1, \max }$ - maximum stress in steel reinforcement, $x_{1}$ - the height of the compressed zone, $w$ - crack opening width.

In the output data, the tensile strength of concrete is conventionally assumed to be close to zero, $f_{c t m}=0,2$ МПа. A similar assumption is made in [9] when calculating crack opening. Table 3 shows the results of a numerical experiment taking into account the work of tensioned concrete between cracks. The designations in the tables are adopted in accordance with [9].

Table 3.

Numerical experiment results $\left(f_{\text {ctm }}=2.02 \mathrm{MPa}\right)$

\begin{tabular}{|l|l|l|l|l|l|}
\hline $\begin{array}{c}\mathrm{P}_{0} \\
\mathrm{MPa}\end{array}$ & \multicolumn{1}{|c|}{$\mathrm{T}_{1},{ }^{\circ} \mathrm{C}$} & \multicolumn{1}{|c|}{$\mathrm{T}_{2},{ }^{\circ} \mathrm{C}^{*}$} & \multicolumn{1}{|c|}{$\sigma_{s 1, \max , \mathrm{MPa}}, \mathrm{mm}$} & $w_{c r c}, \mathrm{~mm}$ \\
\hline 0 & 150 & 60 & 68 & 0,05 & 0,0245 \\
\hline 0,5 & 150 & 60 & 79 & 0,0375 & 0,0339 \\
\hline 1,0 & 150 & 60 & 95 & 0,0125 & 0,0488 \\
\hline 1,5 & 150 & 60 & 148 & 0 & 0,121 \\
\hline 2,0 & 150 & 60 & 226 & 0 & 0,222 \\
\hline 2,0 & 20 & 20 & 223 & 0 & 0,218 \\
\hline
\end{tabular}

Note: * - convective heat transfer on the outer part of the ring (Newton-Richmann boundary condition).

Designation similar to Table 3

The temperature tensile stresses in the reinforcement of the annular specimen, obtained by numerical simulation, significantly depend on the accounting or neglect of the concrete tensile work. Failure to take into account the work of tensioned concrete led to an increase in the level of stresses in the reinforcement from $19-31 \%$ to almost double at normal temperatures.

The experimental crack opening width in annular specimens under the action of internal pressure and temperature load was compared with that obtained in a numerical experiment. At normal temperature, the deviation of the numerical values of the crack opening width from the experimental ones was about $9 \%$, with short-term heating - 19\%, with thermal power loads $16-20 \%$, taking into account the work of concrete between the cracks. The maximum crack opening width of $0.218 \mathrm{~mm}$ did not exceed the limit values in accordance with the current standards [9]. 
The displacements $\Delta$ and deformations of the most compressed and most stretched extreme concrete fibers of the section of annular specimens determined in a numerical experiment are given in Tables 4 and 5.

Table 4.

Displacements and deformations of annular specimen faces $\left(f_{c t m}=0.2 \mathrm{MPa}\right)$

\begin{tabular}{|c|c|c|c|c|c|c|c|c|}
\hline $\begin{array}{c}\mathrm{P}_{0}, \\
\mathrm{MPa}\end{array}$ & $\mathrm{T}_{1},{ }^{\circ} \mathrm{C}$ & $\begin{array}{c}\mathrm{T}_{2},{ }^{*} \\
{ }^{\circ} \mathrm{C}\end{array}$ & $\begin{array}{c}\Delta^{\prime}, \\
\mathrm{mm}\end{array}$ & $\begin{array}{c}\Delta, \\
\mathrm{mm}\end{array}$ & $\begin{array}{c}\sum \varepsilon_{\mathrm{c}(1)} \\
10^{-5}\end{array}$ & $\begin{array}{c}\sum \varepsilon_{\mathrm{c}(2)} \\
10^{-5}\end{array}$ & $\varepsilon_{\mathrm{c}(1)}, 10^{-5}$ & $\varepsilon_{\mathrm{c}(2)}, 10^{-5}$ \\
\hline 0 & 150 & 60 & 0,553 & 0,743 & 138,2 & 123,9 & $-12,0$ & 63,9 \\
\hline 0.5 & 150 & 60 & 0,699 & 0,878 & 174,7 & 146,4 & 24,7 & 86,4 \\
\hline 1,0 & 150 & 60 & 0,937 & 1,098 & 234,3 & 183 & 84,3 & 123 \\
\hline 1.5 & 150 & 60 & 1,176 & 1,318 & 293,9 & 219,7 & 143,9 & 159,7 \\
\hline 2,0 & 150 & 60 & 1,414 & 1,538 & 353,6 & 256,3 & 203,6 & 196,3 \\
\hline 2,0 & 20 & 20 & 0,907 & 0,836 & 226,8 & 139,3 & 226,8 & 139,3 \\
\hline
\end{tabular}

Note: * - convective heat transfer on the outer part of the ring (Newton-Richmann boundary condition)

$\mathrm{P}_{0}$ - internal pressure, $\mathrm{T}_{1}, \mathrm{~T}_{2}$ - respectively the temperatures inside and outside the ring, $\Delta^{\prime}$ and $\Delta$ are, respectively, the radial displacements of the inner and outer parts

кільця, $\sum \varepsilon_{\mathrm{c}(1)}, \sum \varepsilon_{\mathrm{c}(2)}$ - total deformations taking into account thermal expansion

on the inner and outer parts of the ring, $\varepsilon_{\mathrm{c}(1)}, \varepsilon_{\mathrm{c}(2)}$ are the sum of elastic and plastic deformations on the inner and outer parts of the ring, respectively.

Table 5.

Displacements and deformations of annular specimen faces $\left(f_{c t m}=2.02 \mathrm{MPa}\right)$

\begin{tabular}{|l|l|l|l|l|l|l|l|l|}
\hline $\begin{array}{c}\mathrm{P}_{0,} \\
\mathrm{MPa}\end{array}$ & $\begin{array}{l}\mathrm{T}_{1}, \\
{ }^{\circ} \mathrm{C}\end{array}$ & $\begin{array}{c}\mathrm{T}_{2}, * \\
{ }^{\circ} \mathrm{C}\end{array}$ & $\begin{array}{c}\Delta^{\prime}, \\
\mathrm{mm}\end{array}$ & $\begin{array}{c}\Delta, \\
\mathrm{mm}\end{array}$ & $\begin{array}{l}\sum_{\mathrm{c}_{\mathrm{c}(1)},} \\
10^{-5}\end{array}$ & $\begin{array}{l}\sum_{\varepsilon_{\mathrm{c}(2)},} \\
10^{-5}\end{array}$ & $\varepsilon_{\mathrm{c}(1)}, 10^{-5}$ & $\varepsilon_{\mathrm{c}(2),}, 10^{-5}$ \\
\hline 0 & 150 & 60 & 0,494 & 0,688 & 123,6 & 114,6 & $-26,0$ & 54,6 \\
\hline 0.5 & 150 & 60 & 0,530 & 0,720 & 132,5 & 120 & $-18,0$ & 60 \\
\hline 1,0 & 150 & 60 & 0,579 & 0,765 & 144,7 & 127,5 & $-5,3$ & 67,5 \\
\hline 1.5 & 150 & 60 & 0,736 & 0,910 & 184,1 & 151,7 & 34,1 & 91,7 \\
\hline 2,0 & 150 & 60 & 0,974 & 1,130 & 243,5 & 188,3 & 93,5 & 128,3 \\
\hline 2,0 & 20 & 20 & 0,470 & 0,431 & 117,4 & 71,9 & 117,4 & 71,9 \\
\hline
\end{tabular}

Note: * - convective heat transfer on the outer part of the ring (Newton-Richmann boundary condition)

Designation similar to Table 4 
The height of cracks obtained in a numerical experiment using dependence (1) was $75.8 \mathrm{~mm}$ and differed from the experimental values by $18-20 \%$ for all test modes.

$$
\varepsilon_{c t u}=-2 f_{c t m} / E_{c d}
$$

All designations are adopted in accordance with [9]. In this case, the generalized coefficient of the deformation modulus reduction from the temperature of 0.60 at the crack tip was used. Failure to take into account the work of concrete in tension leads to an increase in the deviations of the width of the opening and the height of the cracks in the experimental values. The maximum crack opening width of $0.445 \mathrm{~mm}$ at thermal power loads and $0.486 \mathrm{~mm}$ at normal temperature significantly exceeds the limit values given in the current standards [9].

In the numerical experiment with the first short-term heating and the action of the maximum internal pressure, the radial displacements of the rings were $1.538 \mathrm{~mm}$ without taking into account the work of stretched concrete and $1.13 \mathrm{~mm}$ taking into account stretched concrete. With prolonged heating of the inner face to $150^{\circ} \mathrm{C}$ and the maximum internal pressure, the radial displacements of the rings were $0.743 \mathrm{~mm}$ without taking into account the work of stretched concrete and $0.688 \mathrm{~mm}$ taking into account stretched concrete. Long exposure at a temperature of $150{ }^{\circ} \mathrm{C}$ led to a twofold increase in displacements.

Under thermal and force loads, the principle of superposition was preserved, i.e., the summation of displacements from various factors. Long-term one-sided heating of the rings corresponds to large displacement values, since in this case irreversible plastic deformations of concrete are fully manifested. Comparison of experimental displacements with the results of a numerical experiment showed that for specimens with bar reinforcement, as well as for specimens with external sheet reinforcement [1,3], under short-term exposure to load and temperature, radial displacements can be defined as for structures operating in the elastic stage. With prolonged exposure to temperature loads, calculations should take into account the effect of irreversible plastic deformations.

\section{Conclusions.}

Based on the results of comparing the results of a numerical experiment and experimental studies of crack resistance and deformability of annular specimens under the action of thermoforce loads, their analysis and comparison, the following conclusions can be drawn. 
1.Computer simulation of reinforced concrete three-layer annular fragments of protective structures showed the possibility of using a numerical experiment and existing algorithms in the formulation of a stationary thermoelasticity problem to determine with high accuracy the stress-strain state of samples in the mode of stationary short-term and long-term heating and the action of internal pressure. When using a deformation model that takes into account the work of tensile concrete between cracks, deviations from the experimental data were within 8$20 \%$.

2. The stresses in the reinforcement and concrete of a three-layer annular fragment obtained in a numerical experiment under the action of force and thermo-force loads in the formulation of the stationary thermoelasticity problem showed good agreement with the results of experimental studies on full-scale models. The deviation did not exceed 7-10\% when taking into account the tensile work of the concrete section. Without taking into account such work, deviations exceeded $90 \%$.

3.The nonlinear deformable model adopted in the current standards [9], taking into account the real deformation diagrams of concrete and reinforcement, reliably describes the processes occurring in the structure and allows to unambiguously determine its stress-strain state at all load levels, including the limiting state.

\section{References}

1. Report No.01850016741, research work on the topic "Development and study of strength and deformability of structures of sealing heat storage tanks with the inclusion of a new type of sheet reinforcement in a reinforced concrete section". - Lvov: LOLPI, 1989.- 96 p. (contract No.4172 - responsible performer).

2. L.N. Gakhova. Temperature-induced stresses in reinforced structures. Geodynamics and Stress State of the Earth`s Interior (GSSEI 2017). IOP Conf. Series: Earth and Environmental Science 134 (2018) 012021, doi: 10.1088/1755-1315/134/1/012021.

3. I. I. Karkhut, O. V. Krochak, S. B. Maksimovich. Modeling the reinforced concrete shell with a protective structure. Mathematical modeling and computing. Volume 8, Number 3, 2021, pp. 391-399. DOI: https://doi.org/10.23939/mmc2021.03.391.

4. I.I. Karkhut. Temperature loads on reinforced concrete protective structures. Lviv, 2015, publishing house "LP" - $248 \mathrm{p}$.

5. J.J. Luchko, B.B. Kovalchuk, II Karhut. Thermal stress state of structural concretes, reinforced concrete and reinforced concrete structures and bridges. Lviv, 2020, Publishing House "Svit" - 326 p. 
6. Raghupati Roy, U.S.P. Verma and A.S. Warudcar. Analisis of Massive Reinforced Concrete Ring Beam of Nuclear Containment Structure due to Heat of Hydration. Transactions of the $15^{\text {th }}$ International Conference on Structural Mechanics in Reactor Technology (SMiRT 15). Seoul, Korea, August 15-20, 1999.

7. M. Briffaut, F. Benboudjema, J.M. Torrenti, G. Hanas. Numerical analysis of the thermal active restrained shrinkage ring test to study the early age behavior of massive concrete structures. Engineering structures. Vol. 33, issue 4. April 2011. Pages 1390-1401.

8. M. Slijepcevic, R. Vukomanovic, G. Broceta. Stress distribution in concrete chimneys due to elevated temperatures. $1^{\text {st }}$ International Symposium Students FOr Resilient soCiEty (SFORCE 2018), Novi Sad, September 28-29, 2018. Conference paper, February 2019.

9. DSTU B V.2.6-156:2010 Concrete and reinforced concrete structures made of heavy concrete. Design rules. Kyiv, 2011. State Enterprise "Ukrarchbudinform" - 118 p.

10. Krichevsky A.P. Calculation of reinforced concrete engineering structures taking into account temperature influences - M., 1984. Stroyizdat - 148 p.

11. SNiP 2.03.04-84 Concrete and reinforced concrete structures intended for operation in conditions of exposure to elevated and high temperatures. - M, 1985. Gosstroy of the USSR $54 \mathrm{p}$. 